\title{
A specific targeting signal directs Runx2/Cbfa1 to subnuclear domains and contributes to transactivation of the osteocalcin gene
}

\author{
S. Kaleem Zaidi, Amjad Javed, Je-Yong Choi, André J. van Wijnen, Janet L. Stein, Jane B. Lian \\ and Gary S. Stein ${ }^{\ddagger}$ \\ Department of Cell Biology and Cancer Center, University of Massachusetts Medical School, Worcester, MA 01655-0106, USA \\ *Present address: Department of Biochemistry, School of Medicine, Kyungpook National University, 101 Dong-In Jung-Gu, Daegu 700-422, Korea \\ ‡Author for correspondence (e-mail: gary.stein@umassmed.edu) \\ Accepted 21 May 2001 \\ Journal of Cell Science 114, 3093-3102 (2001) (C) The Company of Biologists Lto
}

\section{SUMMARY}

Key components of DNA replication and the basal transcriptional machinery as well as several tissue-specific transcription factors are compartmentalized in specialized nuclear domains. In the present study, we show that determinants of subnuclear targeting of the bone-related Runx2/Cbfa1 protein reside in the C-terminus. With a panel of $\mathrm{C}$-terminal mutations, we further demonstrate that targeting of Runx2 to discrete subnuclear foci is mediated by a 38 amino acid sequence (aa 397-434). This nuclear matrix-targeting signal (NMTS) directs the heterologous Gal4 protein to nuclear-matrix-associated Runx 2 foci and enhances transactivation of a luciferase gene controlled by Gal4 binding sites. Importantly, we show that targeting of Runx2 to the NM-associated foci contributes to transactivation of the osteoblast-specific osteocalcin gene in osseous cells. Taken together, these findings identify a critical component of the mechanisms mediating Runx2 targeting to subnuclear foci and provide functional linkage between subnuclear organization of Runx 2 and bone-specific transcriptional control.

Key words: Osteoblasts, Transcriptional control, Nuclear matrix, Osteocalcin, Nuclear localization

\section{INTRODUCTION}

Multi-component macromolecular complexes that execute the fundamental nuclear processes of DNA replication, transcription and splicing are organized in discrete subnuclear foci (Lawrence et al., 1989; Nickerson et al., 1995; Stein et al., 2000; Wei et al., 1998; Wei et al., 1999). Specificity of gene expression is conferred by transcription factors that respond to physiological cues and intracellular signals. Many cell-typerestricted transcription factors are targeted to multi-subunit complexes that reside in distinct subnuclear domains (Bidwell et al., 1998; DeFranco and Guerrero, 2000; Stein et al., 2000), and support activation or repression of tissue-specific genes. These macromolecular complexes involved in transcription are dynamic, yet remain stably associated with the nucleus following removal of soluble proteins and chromatin. Examples of regulatory proteins that are targeted to intranuclear foci are Runx/Cbfa/AML factors (Merriman et al., 1995; Stein et al., 2000; Zeng et al., 1997; Zeng et al., 1998), the multi-functional YY1 protein (Guo et al., 1995; McNeil et al., 1998), steroid hormone receptors (glucocorticoid receptor, estrogen receptor, vitamin $\mathrm{D}$ receptor, androgen receptor) (DeFranco and Guerrero, 2000; Getzenberg et al., 1991; Getzenberg and Coffey, 1990; Stenoien et al., 2001; van Steensel et al., 1995a; van Steensel et al., 1995b), Pit1 transcription factor (Mancini et al., 1999), the corepressor transducin-like enhancer (TLE; Javed et al., 2000), histone deacetylases and acetyl transferases (reviewed in Davie, 1997;
Davie, 1998; Davie and Chadee, 1998), and SWI/SNF chromatin-modifying complexes (Reyes et al., 1997). The mechanisms that govern the assembly of these compositely organized, multi-functional complexes at the subnuclear level may be essential for the regulation of gene expression.

Localizing regulatory proteins to specialized sites within the nucleus involves nuclear import, in situ interactions with chromatin and transcriptional co-regulators, and subnuclear targeting. Mechanisms controlling nuclear import and interactions of transcription factors with DNA and coregulators are well defined (Gorlich and Kutay, 1999; Gorlich and Mattaj, 1996; Lemon and Tjian, 2000). However, molecular determinants that target regulatory factors to specific subnuclear domains involved in transcription remain to be identified.

Modifications in multiple parameters of nuclear architecture occur during progression of osteoblast differentiation, as reflected by subnuclear compartmentalization of gene regulatory proteins (Bidwell et al., 1993; Dworetzky et al., 1990) and alterations in chromatin structure of the bonespecific osteocalcin gene (Montecino et al., 1994; Montecino et al., 1996b; Montecino et al., 1996a; Montecino et al., 1999b; Montecino et al., 1999a). Bone-restricted expression of the osteocalcin gene provides a paradigm for defining the mechanisms underlying tissue-specific transcription in the context of nuclear and chromatin architecture. Two osteocalcin gene regulatory factors, nuclear matrix protein 1 (NMP1) and NMP2, have been identified as YY1 and Runx2/Cbfa1, 
Fig. 1. Endogenous Runx2 is associated with the nuclear matrix in osteoblastic cells. ROS 17/2.8 cells grown on gelatin-coated coverslips were processed for whole cell (WC) or nuclear matrixintermediate filament (NMIF) preparations and in situ immunofluorescence as described in Materials and Methods. Rabbit polyclonal antibody against Runx 2 was used at a dilution of 1:200 (Javed et al., 2001).

Secondary antibody used was Alexa 468 (goat against mouse) at a dilution of 1:800. The middle panel shows 4',6diamidino-2-phenylindole (DAPI) staining, which is absent in NM-IF preparation as chromatin has been removed. Right panel shows phase contrast image of the same cell.
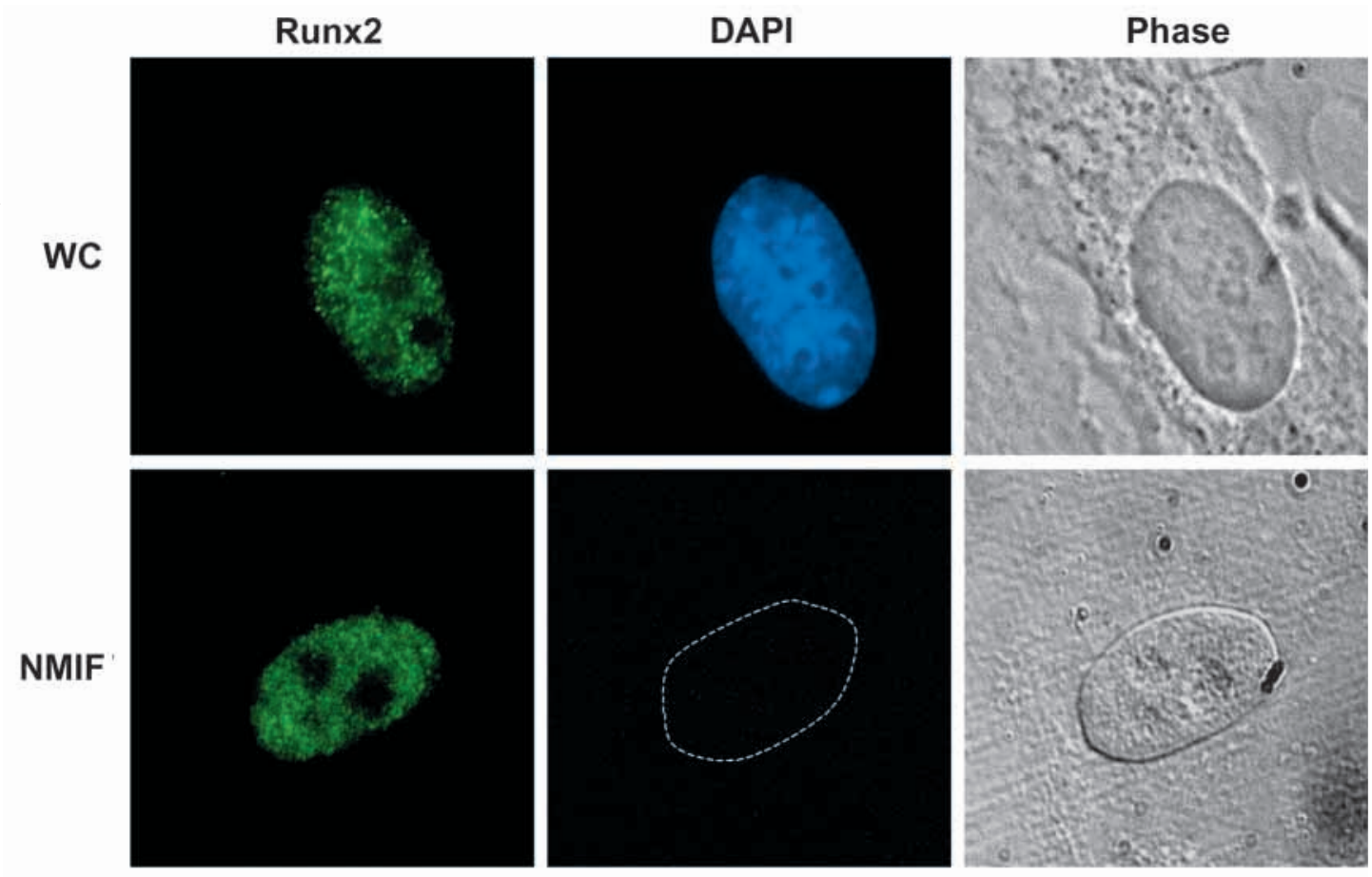

respectively (Guo et al., 1995; Merriman et al., 1995). Both factors are intimately associated with control of steroidhormone-responsive and tissue-specific transcription (Guo et al., 1997; Javed et al., 1999), suggesting functional coupling between cell signaling and nuclear architecture.

The Runx/Cbfa proteins (e.g. Runx1/AML-1, Runx2/Cbfa1) play vital roles in cellular differentiation and development. Gene ablation studies have revealed that Runx 1 is required for definitive hematopoiesis whereas Runx2 is essential for bone formation (Komori et al., 1997; Otto et al., 1997; Wang et al., 1996). Runx proteins interact with the core DNA sequence (RACCRCW) through the highly conserved runt homology domain (Meyers et al., 1993; Ogawa et al., 1993). These proteins exert their effects in part by modifying chromatin organization of tissue-specific gene promoters (Gutierrez et al., 2000; Javed et al., 1999; Montecino et al., 1996b). In addition, the activities of Runx factors are modulated by interactions with coregulatory proteins (e.g. Groucho/TLE, Yes-associated protein (YAP), Smad) that contribute to the integration of cellsignaling pathways in response to physiological cues (Aronson et al., 1997; Hanai et al., 1999; Javed et al., 2000; Levanon et al., 1998; McLarren et al., 2000; Yagi et al., 1999; Zhang et al., 2000a). Runx proteins reside in discrete subnuclear foci and colocalize with transcriptional regulators which activate or repress Runx-dependent genes (Javed et al., 2000; Prince et al., 2001; Zeng et al., 1997; Zeng et al., 1998).

The identification of Runx2/Cbfa1 as a nuclear-matrixassociated tissue-specific transcription factor (Banerjee et al., 1997; Bidwell et al., 1993; Ducy et al., 1997; Merriman et al., 1995) provided the initial insight into the linkage between subnuclear compartmentalization and osteoblast differentiation. Therefore, one important question is how Runx2 is directed to specific subnuclear domains and whether intranuclear localization contributes to regulation of bonespecific genes. In the present study, we have defined a 38 amino acid segment in the C-terminus of Runx 2 that is responsible for subnuclear targeting of the transcription factor. Moreover, this nuclear-matrix-targeting signal (NMTS) is sufficient to direct a heterologous protein to the nuclear-matrix-associated foci containing Runx2. Furthermore, subnuclear targeting of Runx2 contributes to transcriptional regulation of the bonespecific osteocalcin gene.

\section{MATERIALS AND METHODS}

\section{Cell cultures and transient transfections}

Rat osteosarcoma ROS 17/2.8 and human cervical carcinoma HeLa cells were maintained and transfected essentially as reported previously (Javed et al., 2000).

\section{Plasmid constructs}

An epitope tag version of pcDNA 3.1 (pHA) was generated by inserting the HA-tag in the HindIII-KpnI sites to replace the HisXpress tag of pcDNA 3.1 (Invitrogen, Carlsbad, CA). HA-tag Runx2 was constructed by cloning a cDNA encoding Runx2 in the BamHI$X b a \mathrm{I}$ sites of pHA to generate pHA-Runx2 (1-528). pHA-Runx2 (1$516)$ was generated by digesting pHA-Runx 2 (1-528) with EcoRI and $X b a I$ followed by fill-in reaction with DNA polymerase I Klenow fragment and blunt end ligation. pHA-Runx2 (1-376) was generated by the addition of a stop codon by PCR-based site-directed mutagenesis. The Runx2 mutant $\Delta 397-434$ was constructed by PCRbased nest-deletion mutagenesis. Internal deletions of Runx2, that is, $\Delta 400-467$ and $\Delta 433-467$, were generated by digesting pHA-Runx 2 with SmaI and BspmI-SmaI, respectively. To generate Gal4 DNAbinding domain (DBD) (1-147) fused with Runx2 (397-434), the aforementioned fragments of Runx 2 were amplified with EcoRV-Pst I sites incorporated into the primers and the digested PCR products were inserted in frame downstream of the Gal4 DBD. The reading frames of deletion mutants were confirmed by sequencing.

\section{Nuclear extracts and electrophoretic mobility shift assay}

Preparation of nuclear extracts from cells expressing proteins of interest and the protocol for electrophoretic mobility shift assays have been described (Javed et al., 1999). The wild-type Runx consensus 5' 


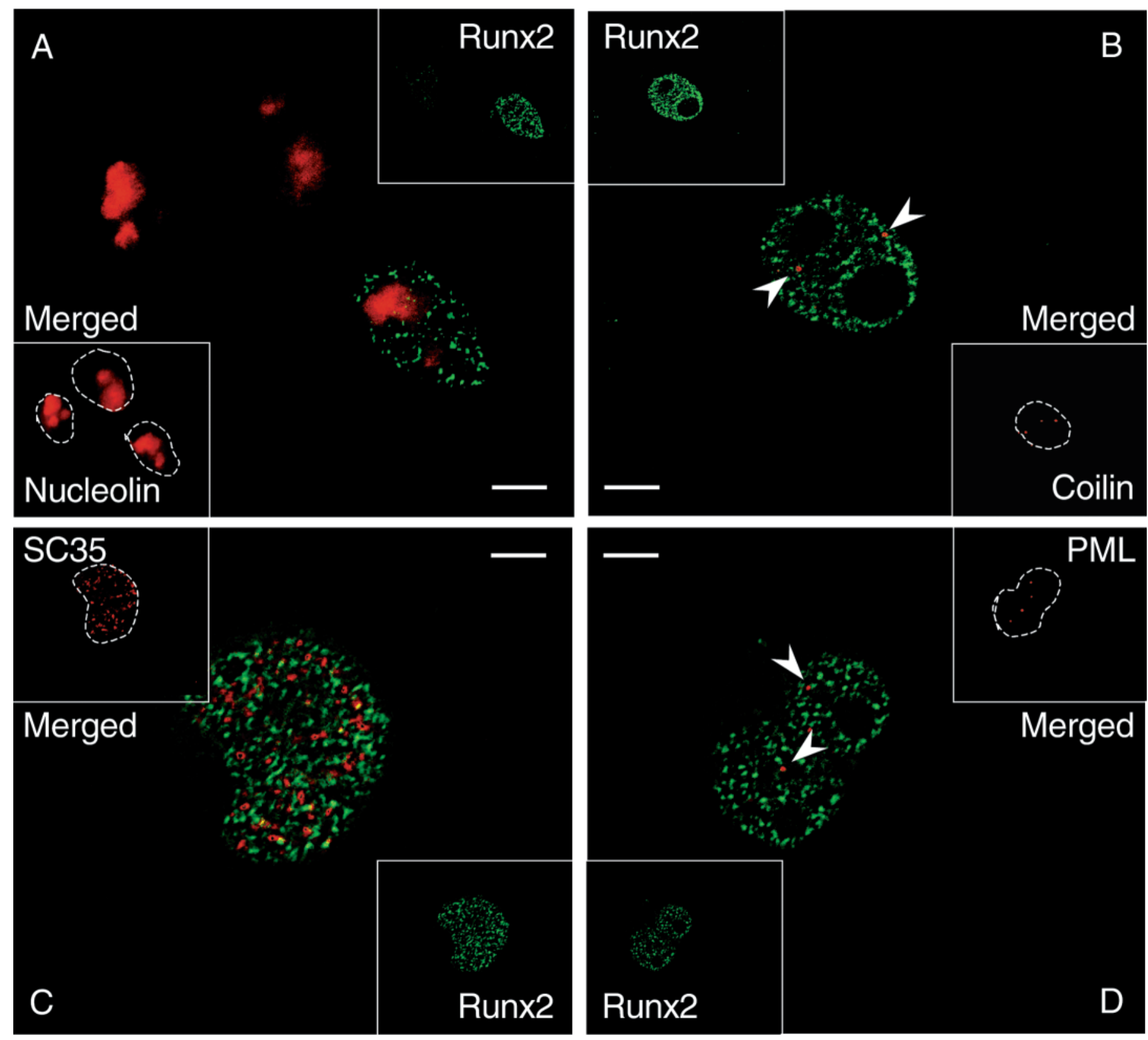

Fig. 2. Runx2 resides in distinct subnuclear domains. HeLa cells transiently expressing Runx2 were processed for NM-IF preparation and doublelabel immunofluorescence to assess to what extent it colocalizes with nucleolin (A), coilin (B), SC35 (C) and PML bodies (D). Arrowheads point to distinct coilin and Runx2 domains (B) and PML bodies and Runx2 (D). Bars ( $2 \mu \mathrm{m})$ represent the relative magnification of the images.

CGAGTATTGTGGTTAATACG 3' (Meyers et al., 1993) was synthesized using a Beckman synthesizer 2000. The Runx binding site is indicated in bold.

\section{In situ immunofluorescence microscopy}

ROS $17 / 2.8$ or HeLa cells grown on gelatin-coated coverslips were transfected with $0.5 \mu \mathrm{g}$ cytomegalovirus (CMV)-driven wild-type Runx2, its deletion mutants or with expression constructs for Gal4 DBD fused to the NMTS of Runx2. Cells were extracted for in situ nuclear matrix preparations and were analyzed by digital microscopy essentially as described (Javed et al., 2000). HA-tag full-length or deletion mutants of Runx 2 were detected by a mouse monoclonal antibody against HA-tag at a dilution of 1:3000 (Zeng et al., 1997). Expression of the Gal4 DBD fusion constructs was detected by a mouse monoclonal antibody against Gal4 DBD (Santa Cruz
Biotechnology Inc., Santa Cruz, CA) at a dilution of 1:1000. We used either Alexa 488 anti-rabbit or Alexa 568 anti-mouse secondary antibodies (Molecular Probes, Eugene, OR). To detect endogenous Runx2 in ROS 17/2.8 cells, the rabbit polyclonal antibody (Javed et al., 2001) was used at a dilution of 1:200. Mouse monoclonal antibodies were used to detect SC35, RNA processing speckles (1:500) (Spector et al., 1991), promyelocytic leukemia (PML) bodies (1:1000; Santa Cruz Biotechnology Inc.), coilin (1:100 (Smith et al., 1995)) and nucleolin (1:300; provided by P.-K. Chan, Baylor College of Medicine, TX).

\section{Biochemical fractionation and western blotting}

Cells were biochemically fractionated using a protocol previously described (Merriman et al., 1995), with several modifications. HeLa cells grown on $100 \mathrm{~mm}$ plates were transfected with $10 \mu \mathrm{g}$ of full-length 
Fig. 3. Deletion mutants of Runx 2 express at comparable levels and exhibit unaltered DNA binding activity.

(A) Runx 2 deletion mutants. The black box shows highly conserved runt homology domain (RHD). The dark gray box represents the amino acid sequences in Runx2 homologous to the NMTS of Runx 1 whereas the C-terminal light gray box represents the highly conserved VWRPY domain. (B) HeLa cells grown in $100 \mathrm{~mm}$ plates were transfected at 50-60\% confluence with $10 \mu \mathrm{g}$ of the expression construct for each of the mentioned deletion mutants. The cells were harvested 24 hours after transfection in direct lysis buffer and proteins were separated by SDS-PAGE. The western blotting was carried out as described. The blots were incubated with monoclonal antibody against HA tag (Santa

A

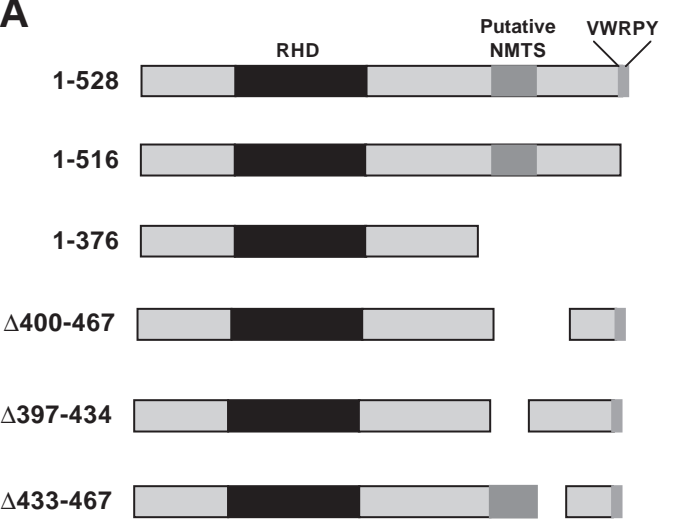

C

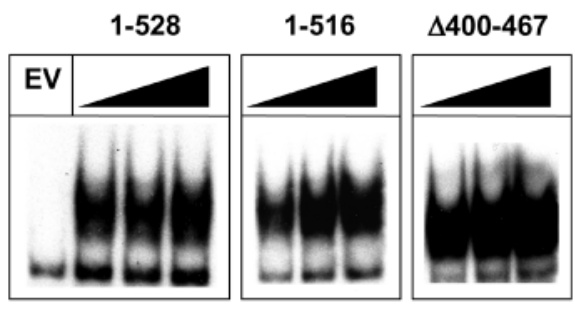

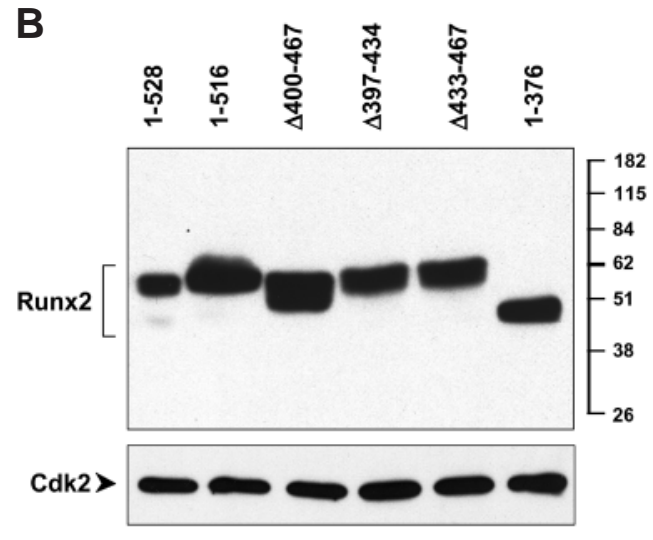

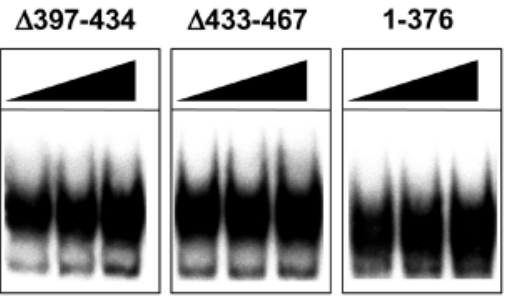

Cruz; dilution 1:3000) followed by incubation with HRP-conjugated secondary antibody raised against mouse (Santa Cruz; dilution 1:2000) to detect the proteins. Cdk2 antibody (1:5000) was used as an internal control. (C) HeLa cells transiently expressing mentioned deletion mutants were processed for nuclear extract preparation. Radioactively labeled Runx consensus sequence was used as probe. The mentioned proteins were used in increasing concentrations, that is, 2,4 and $8 \mu \mathrm{g}$ in electrophoretic mobility shift assay; EV (empty vector) indicates that cells were transfected with vector backbone.

Runx 2 or deletion constructs and subcellular fractions were prepared 24 hours after transfection. For whole-cell lysate, cells were harvested in $300 \mu \mathrm{l}$ direct lysis buffer ( $2 \%$ SDS, $2 \mathrm{M}$ urea, $10 \%$ glycerol, $10 \mathrm{mM}$ Tris-HCl (pH 6.8), $0.002 \%$ bromophenol blue, $10 \mathrm{mM}$ DTT and $1 \times$ Complete ${ }^{\mathrm{TM}}$ protease inhibitors (Roche, Indianapolis, IN)). Samples were immediately boiled for 5 minutes and stored at $-70^{\circ} \mathrm{C}$ until used. For subcellular fractionation, cells were collected in ice-cold $1 \times$ PBS containing $1 \times$ Complete $^{\mathrm{TM}}$ protease inhibitors. Cell pellets were resuspended in $300 \mu \mathrm{l} \mathrm{CSK}$ buffer $(100 \mathrm{mM} \mathrm{NaCl}, 0.3 \mathrm{M}$ sucrose, 10 $\mathrm{mM}$ Pipes, $3 \mathrm{mM} \mathrm{MgCl} 2,1 \mathrm{mM}$ EGTA, 0.5\% Triton X-100, $\mathrm{pH}$ 6.8) for 10 minutes on ice. Extracted cells were then subjected to centrifugation to collect nuclei. The supernatant containing cytosolic proteins was frozen in liquid nitrogen and stored in aliquots at $-70^{\circ} \mathrm{C}$. Nuclei were extracted with $300 \mu$ digestion buffer $(50 \mathrm{mM} \mathrm{NaCl}, 0.3$ M sucrose, $10 \mathrm{mM}$ Pipes, $3 \mathrm{mM} \mathrm{MgCl} 2,1 \mathrm{mM}$ EGTA, $0.5 \%$ Triton X100, pH 6.8) containing $400 \mathrm{U}$ DNaseI (Roche) for 30 minutes at room temperature. DNaseI activity was stopped by adding $2 \mathrm{M}$ ammonium sulfate to a final concentration of $250 \mathrm{mM}$ for 5 minutes at room temperature. Extracted nuclei were centrifuged to separate soluble nuclear proteins (chromatin fraction) and insoluble nuclear-matrixintermediate filament fraction (NM-IF). The NM-IF fraction was then boiled in $300 \mu \mathrm{l}$ of direct lysis buffer for 5 minutes. The same volume percentage of each fraction was analyzed by $10 \%$ SDS-PAGE. Separated proteins were transferred to a PVDF membrane (Millipore) and processed for western blotting as described elsewhere (Ausubel et al., 1997). Antibodies were purchased from Santa Cruz and used in the following dilutions: monoclonal antibody against HA tag (SC-7392; 1:3000), goat polyclonal antibody against lamin B (SC-6217; 1:1000), and the corresponding horse-radish peroxidase (HRP)-conjugated secondary antibodies (SC-2042; 1:2000). Immunoreactivity was assessed using an ECL chemiluminescence kit (Amersham-Pharmacia, Piscataway, NJ).

\section{Reporter gene activity assays}

Rat osteosarcoma (ROS 17/2.8) or HeLa cells grown on six-well plates were transfected with $0.1 \mu \mathrm{g}$ of expression vector for Runx 2 or its deletion mutants along with $1 \mu \mathrm{g}$ of -208 osteocalcin-CAT (OCCAT), spanning one Runx-binding site (site C) (Banerjee et al., 1996; Javed et al., 1999) of the rat osteocalcin promoter. Rous sarcoma virus-luciferase (RSV-Luc) was included as an internal control for transfection efficiency. Cells were harvested 24 hours after transfection and were processed for CAT (chloramphenicol acetyl transferase) assays as described (Javed et al., 1999). All quantitation was done on the Storm PhosphorImager using ImageQuant software (ABI/Molecular Dynamics, Sunnyvale, CA). The luciferase activity was assessed with Luciferase Assay Kit (Promega, Madison, WI) from the same cell lysate. CAT values were normalized with respect to the luciferase values. The graphs are representative of three independent experiments ( $n=6$ in each experiment) with different DNA preparations.

\section{RESULTS}

\section{Runx2 resides in unique subnuclear domains}

To address the mechanism that directs bone-tissue-related Runx 2 protein to nuclear-matrix-associated foci, we initially assessed the subnuclear distribution of endogenous Runx2 in ROS 17/2.8 cells. As shown in Fig. 1, endogenous Runx2 protein is localized in numerous punctate subnuclear foci and remain associated with the NM-IF scaffold following detergent extraction and chromatin removal.

We assessed whether Runx 2 colocalizes with previously established subnuclear domains or whether it is distributed 
Fig. 4. The region responsible for subnuclear targeting of Runx 2 resides in the C-terminus. ROS 17/2.8 cells grown on gelatin-coated coverslips were transfected with (A) Runx2 (1-528) (B) Runx2 (1-516) and (C) Runx2 (1-376). The cells were then processed for NMIF preparation and in situ immunofluorescence. The coverslips were incubated with monoclonal antibody against HA tag (1:3000) followed by incubation with Alexa 568 conjugated secondary antibody $(1: 800)$ to detect the expressed proteins. Images were taken using Zeiss Axioplan digital microscope and Metamorph software was used for bio imaging. Bars $(2 \mu \mathrm{m})$ represent the relative magnification of the images.

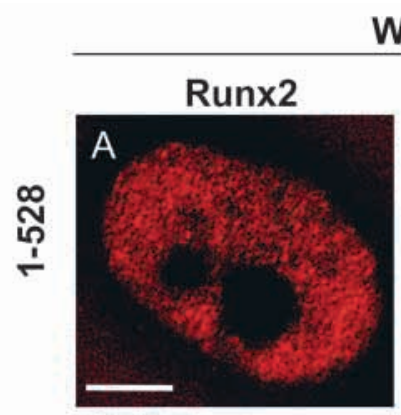

WC
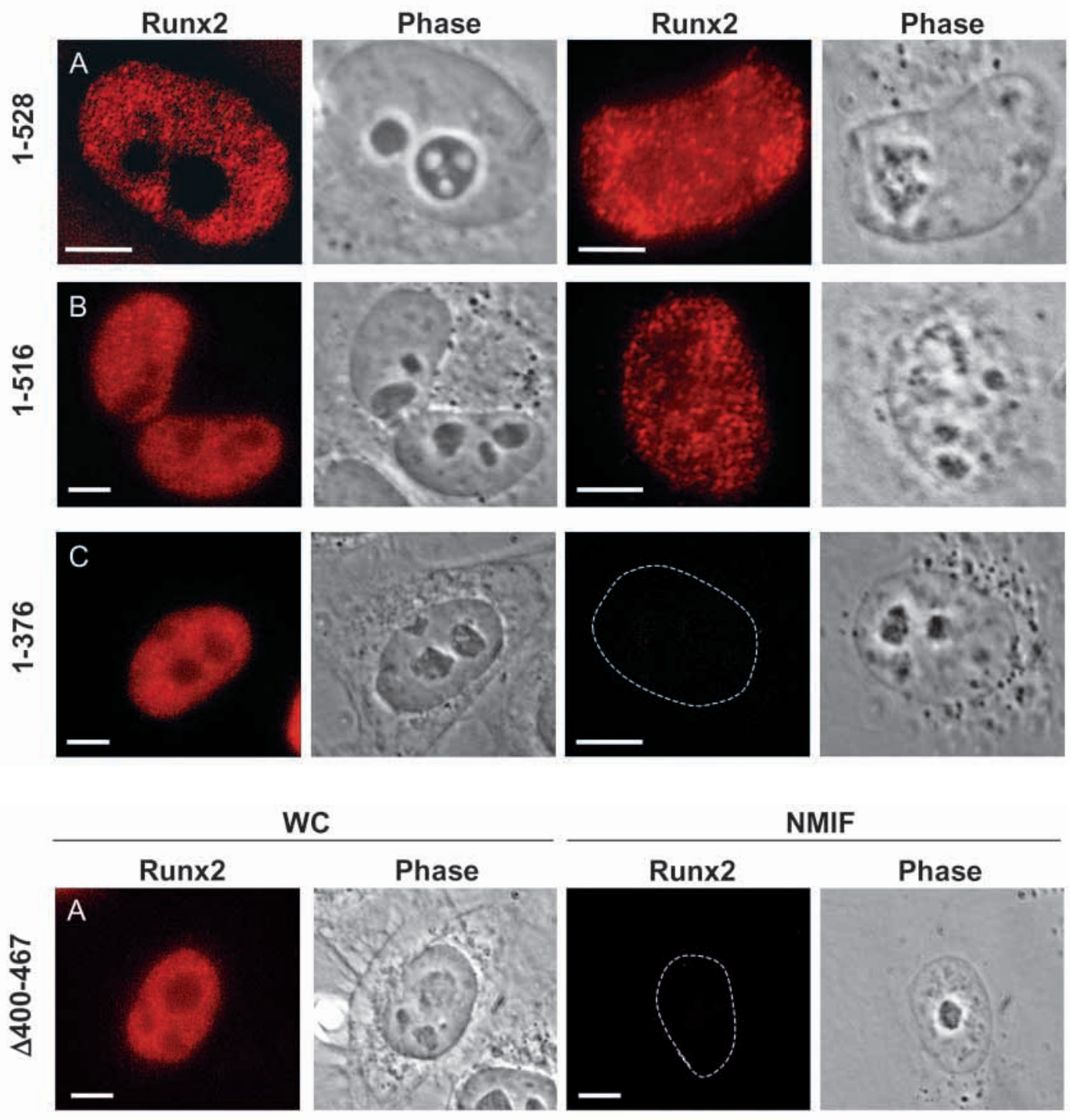

WC
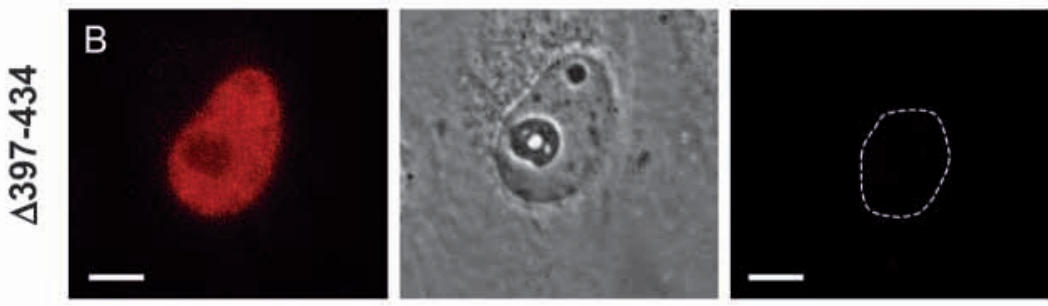

NMIF
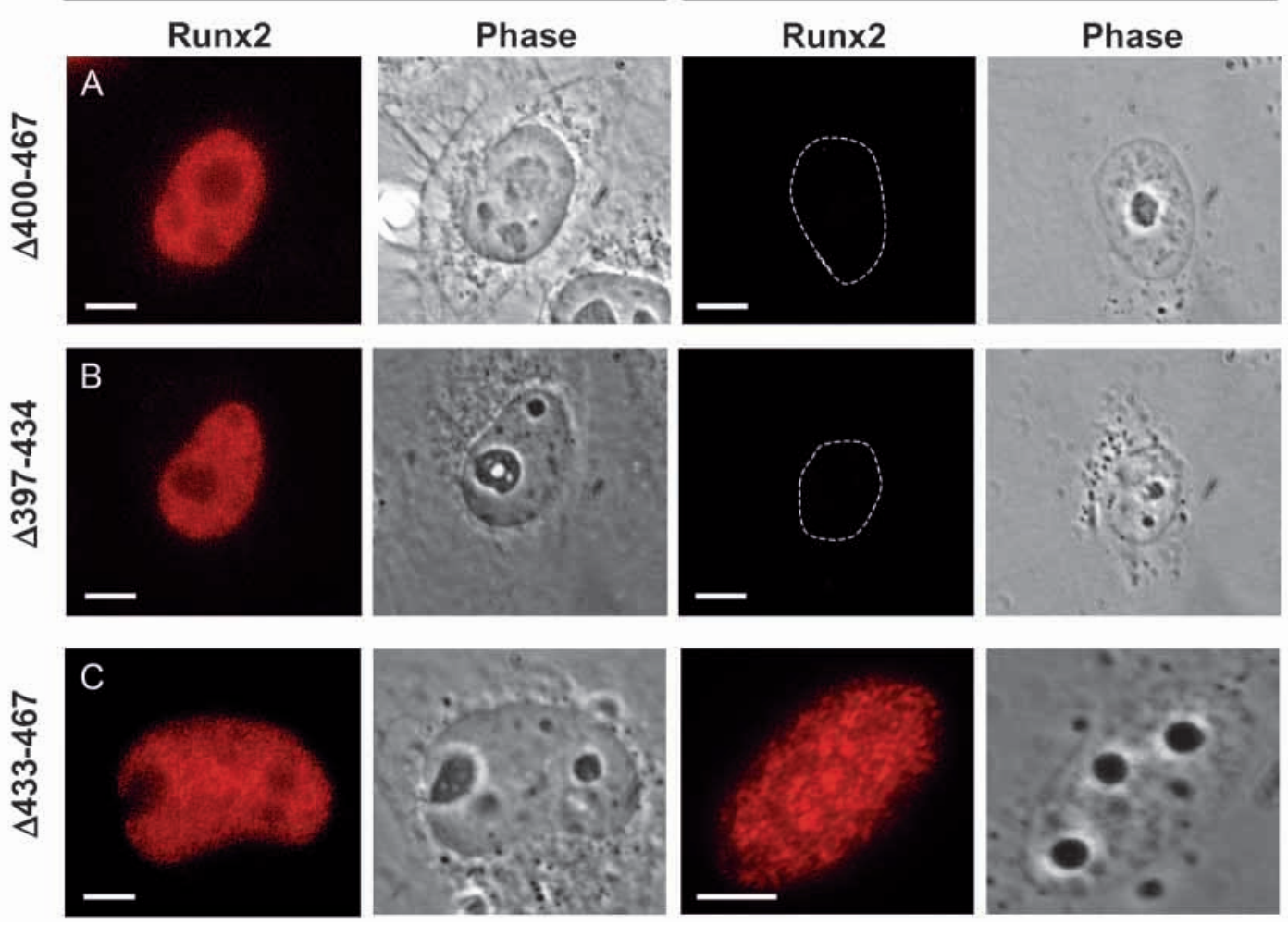
(B) Runx2 (397-434) and (C) Runx2 (433-467). The cells were then processed for NMIF preparation and in situ immunofluorescence as for Fig. 4. Bars $(2 \mu \mathrm{m})$ represent the relative magnification of images.

in distinct foci. Cells transiently expressing Runx2 were evaluated for the relative location of Runx 2 and endogenous PML bodies (Chang et al., 1995), SC35 RNA processing speckles (reviewed by Shopland and Lawrence, 2000), nucleolar protein nucleolin (Dickinson et al., 1992) or coiled body protein coilin (Puvion-Dutilleul et al., 1995) by immunofluorescence microscopy. To facilitate antibody compatibility, we prepared a construct expressing epitope 
tagged Runx2 and transfected into HeLa cells that lack endogenous Runx2. As shown in Fig. 2, Runx2 does not colocalize with any of these proteins, indicating that Runx2 resides in unique subnuclear domains.

\section{Delineation of the NMTS of Runx2}

To delineate the region of Runx 2 responsible for nuclear matrix targeting, several deletion mutants of Runx 2 were generated. All of the deletion mutants showed comparable levels of expression and exhibited normal DNA binding activity (Fig. 3). We analyzed the in situ subnuclear localization of these Runx2 mutants in nuclear matrix preparations of ROS 17/2.8 and HeLa cells. As shown in Fig. 4A, transiently expressed full-length Runx2 (1-528) is distributed in discrete subnuclear foci and is resistant to high salt extraction. Deletion of 12 amino acids (1516), which removes the highly conserved VWRPY domain, has no effect on NM association of the protein (Fig. 4B). The VWRPY domain is responsible for interaction with the highly conserved Groucho/TLE class of repressors, which also associate with the NM (Chen and Courey 2000; Javed et al., 2000). The presence of Runx 2 mutant lacking the VWRPY domain (1-516) in the NM-IF preparation indicates that Groucho/TLE proteins are not required for retention of Runx2 in NM-associated foci. Strikingly, removal of amino acids 377 to 528 in the C-terminus in Runx2 mutant (1-376) does not influence competency for nuclear import, but subnuclear retention of this Runx 2 mutant is abrogated. Taken together, these results demonstrate that the sequences responsible for subnuclear distribution of Runx 2 are distinct from those for nuclear import and that the determinants of subnuclear targeting reside in the $\mathrm{C}$-terminal region of the protein (Fig. 4C).

We applied both in situ immunofluorescence and biochemical approaches to delineate the specific amino acid sequences of Runx2 responsible for intranuclear localization (Fig. 5; Fig. 6). Several internal deletion mutants of Runx2 were examined. The results indicate that deletion of aa 400467 abolishes the association of Runx2 ( $\Delta 400-467)$ with subnuclear foci in the nuclear matrix (Fig. 5A). Deletion of amino acids 397-434 eliminates NM association of Runx2 $(\Delta 397-434)$ (Fig. 5B), whereas removal of amino acids 433467 does not affect association of the protein with the NM-IF scaffold (Fig. 5C). Thus, our results establish that a 38 amino acid segment of Runx2 is required for in situ subnuclear targeting. We also monitored the biochemical partitioning of Runx2 protein among cytoplasmic, chromatin and nuclear

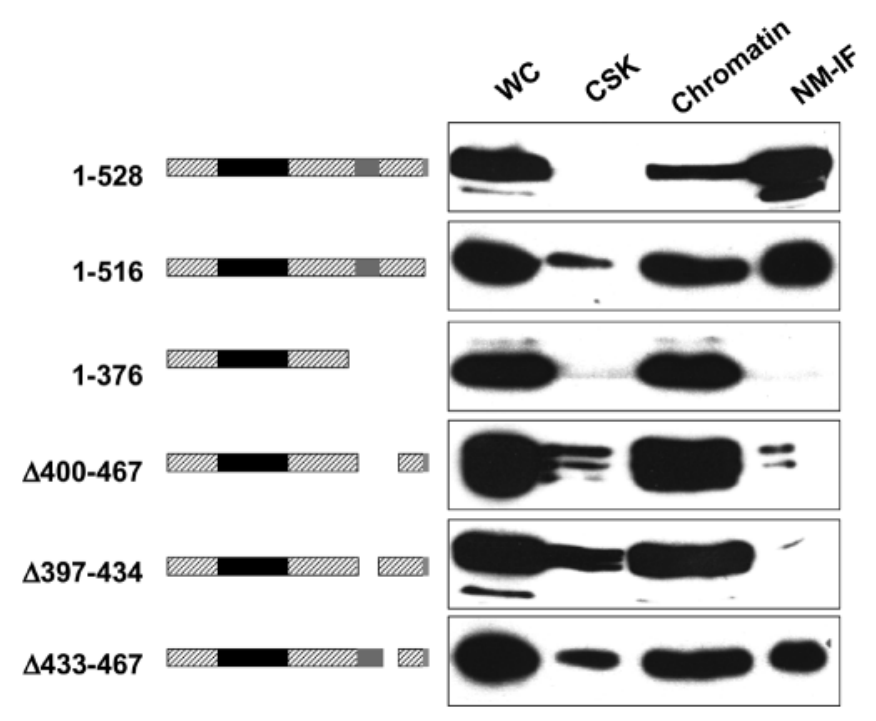

Fig. 6. Subcellular fractionation of HeLa cells expressing deletion mutants of Runx2. HeLa cells expressing mentioned deletion mutants were subjected to biochemical fractionation as detailed in Materials and Methods. The fractions were processed for SDS-PAGE followed by western blotting. Monoclonal antibody against HA tag was used to detect the expressed proteins.

matrix compartments by western blot analysis of subcellular fractions from cells transiently expressing Runx2 deletion mutants (Fig. 6). Mutant proteins containing amino acids 397434 are detected in the NM-IF compartment, but mutants lacking this region [i.e. Runx2 (1-376), Runx2 ( $\Delta 400-467)$, Runx2 ( $\Delta 397-434)]$ are observed only in the cytoplasmic (CSK) and/or chromatin fractions. For comparison, lamin B, a component of the lamina pore complex, is exclusively detected in the NM-IF indicating that principal parameters of nuclear architecture have been preserved (data not shown). We conclude that deletion of the NMTS dramatically alters the subnuclear compartmentalization of Runx 2 mutant proteins. The NMTS region is phylogenetically conserved in diverse vertebrate species (Fig. 7), which is consistent with the importance of the NMTS in intranuclear targeting.

\section{The NMTS of Runx2 can target a heterologous protein to Runx foci}

We directly addressed the ability of the Runx2 NMTS to target
Fig. 7. Conservation of the nuclear matrixtargeting signal in vertebrate species. Amino acid sequence alignments of the indicated Runx2 (Cbfa1/AML3), Runx1 (Cbfa2/AML1), and Runx 3

(Cbfa3/AML2/PEBP2 $\alpha$ A) proteins from different vertebrate species including two species of fish (Danio rerio (Danio), zebrafish; Oryzias latipes (Oryzi), Japanese killifish or medaka). Alignments were performed using CLUSTALW and graphically depicted using the GeneDoc software developed by K. B. Nicholas and H. B. Nicholas. Amino acids were colored on the basis of similarities in physiochemical properties (H,K,R, dark blue; N,Q, light blue; S,T, orange; L,I,V, dark gray, A,G, light gray; F,Y,W, maroon; M,C, yellow; P, white). None of the amino acid sequences contains negatively charged amino acids (D,E).

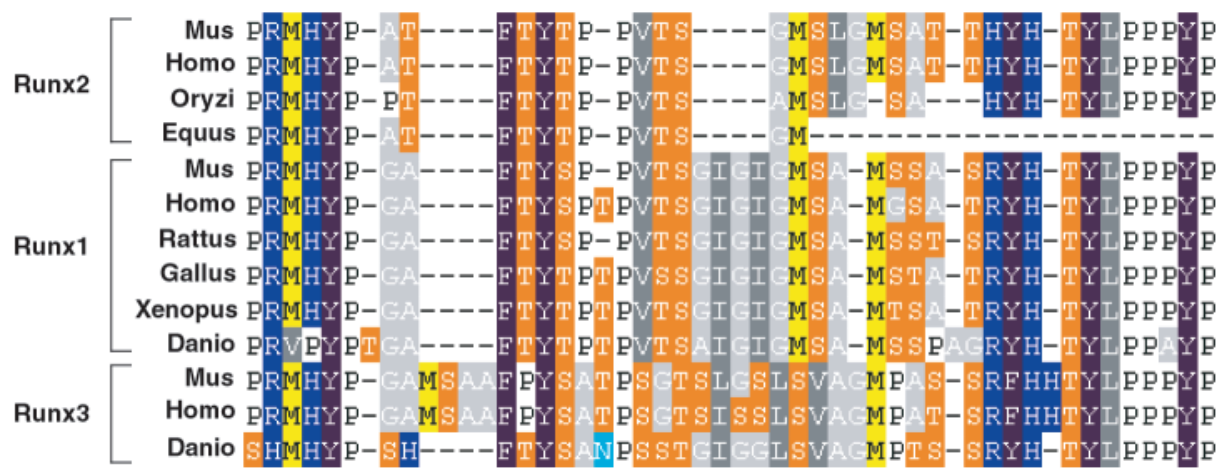


A

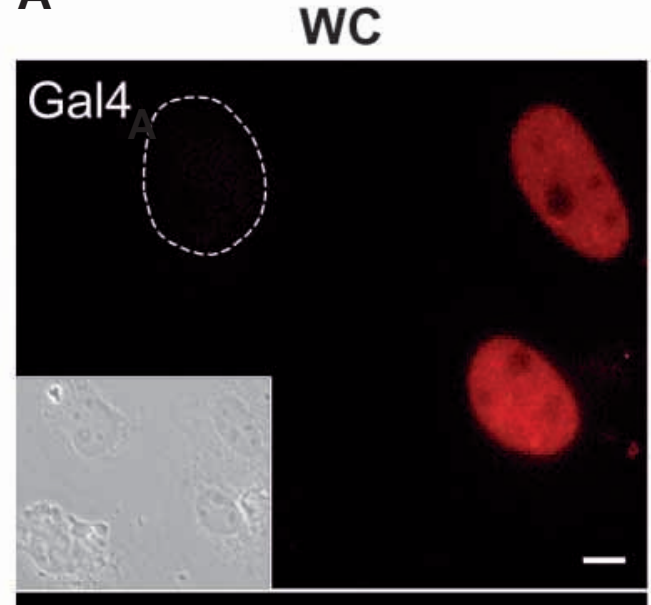

\section{Gal4-NMTS}

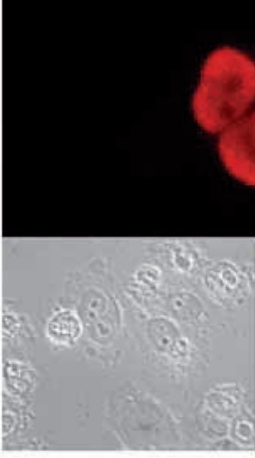

B

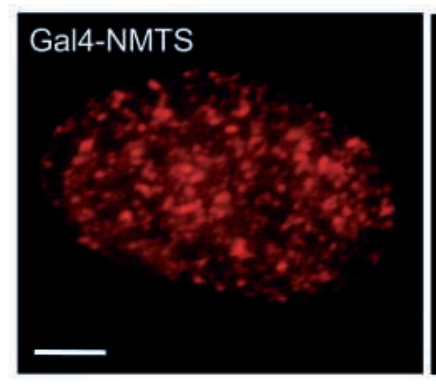

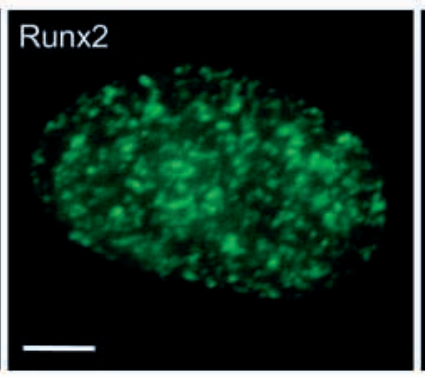

NMIF

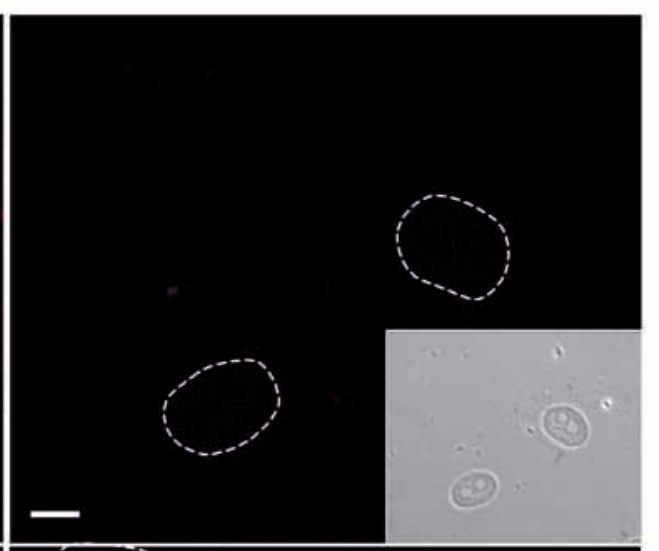

(1)
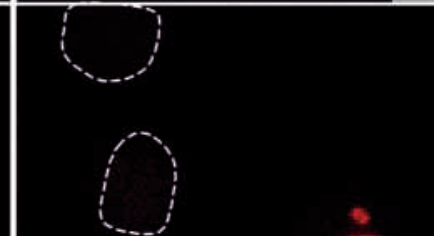

C
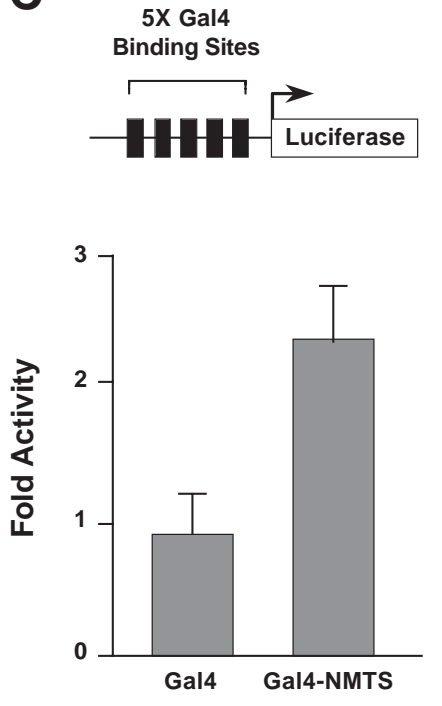

Fig. 8. (A) The NMTS of Runx2 is functionally autonomous. HeLa cells grown on coverslips were transfected with Gal4 or Gal4NMTS Runx2 and the cells were then processed for NM-IF preparation and in situ immunofluorescence as described. The expression of the proteins was detected by monoclonal antibody against Gal4 DBD (1:1000). (B) The NMTS of Runx 2 can target a heterologous protein to the NM-associated Runx2 foci. ROS 17/2.8 cells grown on gelatin-coated coverslips were transfected with Gal4-NMTS Runx2 and were processed for double immuno labeling for endogenous Runx2 and over-expressed Gal4 DBD constructs. (C) The NMTS of Runx2 exhibits mild transactivation. The HeLa cells stably transfected with luciferase reporter carrying five Gal4

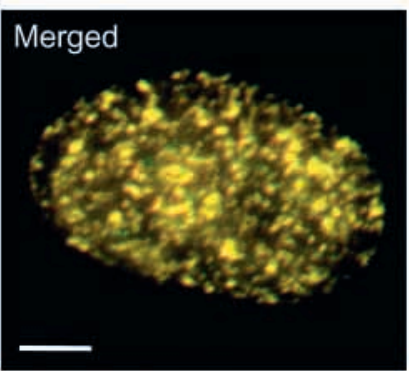

binding sites upstream of transcription initiation site were transiently transfected with Gal4 DBD or Gal4-NMTS. Cells were harvested in reporter lysis buffer 24 hours after transfection and assayed for luciferase activity as described.

a heterologous protein to NM-associated Runx2 foci. We generated a construct encoding a protein in which the NMTS is fused to the Gal4 DNA binding domain (Gal4-NMTS). Cells were transfected with constructs expressing the Gal4 DNA binding domain alone or with the Gal4-NMTS fusion protein. The subcellular distribution of these proteins was analyzed in whole-cell and NM-IF preparations by immunofluorescence microscopy (Fig. 8A). Both proteins are imported into the nucleus, which is consistent with the presence of a nuclear import signal. However, only the Gal4 protein that is fused with the 38 amino acid NMTS is retained in the NM-IF preparations. Our results establish that the Runx2 NMTS functions as an autonomous subnuclear targeting signal.

To assess whether the NMTS can specify the subnuclear location of a heterologous protein, we tested the ability of the NMTS to target the Gal4 protein to the same subnuclear foci as those containing the endogenous Runx 2 in osseous cells. We performed double-label immunofluorescence microscopy and compared the signals of the Gal4-NMTS protein with those for Runx2 (Fig. 8B). We observed that the NMTS of Runx2 targets Gal4 to NM-associated foci where the endogenous Runx2 resides as evidenced by a complete overlap of signals in the merged image. Therefore, our data strongly suggest that the NMTS not only mediates interactions with components of nuclear architecture but also specifies the subnuclear location of the protein.

We assessed whether subnuclear targeting of the Gal4 DBD is functionally linked to transcriptional control of a Gal4-responsive 


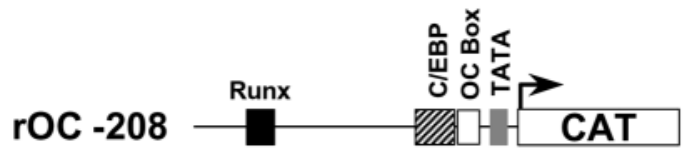

Fig. 9. Transactivation of bone-tissue-specific marker, osteocalcin, is dependent on association of Runx2 with nuclear matrix. HeLa cells grown on six- well plates were transfected with $0.1 \mu \mathrm{g}$ of the mentioned expression constructs along with $1 \mu \mathrm{g}$ p208 OC CAT and $0.05 \mu \mathrm{g}$ RSV-Luc as internal control for transfection efficiency. Cells were harvested in $300 \mu 1$ of $1 \times$ Reporter Lysis Buffer (Promega) and the lysates were processed for CAT and luciferase assays as described. The CAT values were normalized with respective luciferase values and were plotted as fold activity relative to empty vector control. The graph is representative of three independent experiments each with $n=6$ ( \pm s.e.m.). An example of a typical CAT assay is shown.
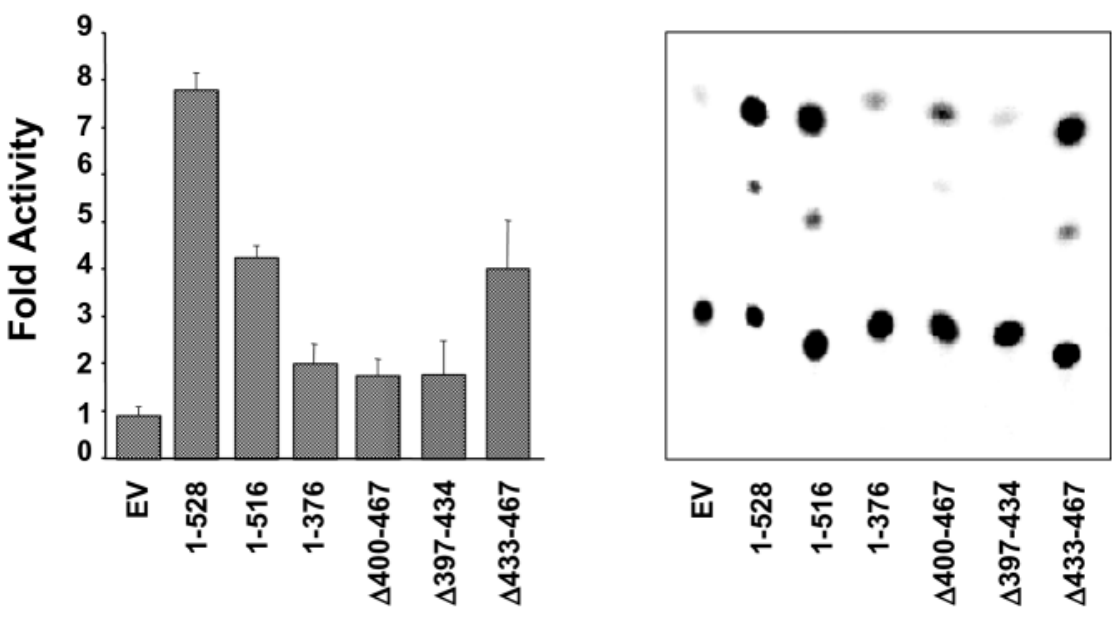

promoter. We transfected the Gal4 DBD or the Gal4-NMTS into HeLa cells containing a genomically integrated luciferase gene driven by Gal4 binding sites. As shown in Fig. 8C, the Gal4NMTS protein mediates 2.5 -fold activation relative to Gal4 DBD alone. Thus, our data indicate that the NMTS supports transcriptional activation of a Gal4-responsive promoter.

\section{The NMTS of Runx2 contributes to activation of the bone-specific osteocalcin gene}

We addressed the biological consequences of NMTS-mediated intranuclear targeting of Runx 2 on osteoblast-specific gene expression. We compared the transcriptional activities of wildtype Runx 2 and mutants lacking the NMTS by monitoring their ability to enhance promoter activity of the rat osteocalcin gene (Fig. 9). Wild-type Runx2 (1-528) activates osteocalcin gene transcription 7-8 fold. This response is reduced to 1.5-2 fold for the Runx2 (1-376) mutant, which lacks the entire C-terminus spanning the NMTS. This result demonstrates that the entire Cterminus of Runx 2 is required for optimal physiological activity of the protein. Runx 2 mutants missing only the NMTS $(\Delta 397$ $434)$ or 68 amino acids including the NMTS $(\Delta 400-467)$ exhibit dramatically reduced transactivation potential - similar to the Runx2 mutant (1-376) - compared to wild-type Runx2 (1-528). Runx 2 mutants in which other segments of the C-terminus were deleted (i.e. Runx2 ( $\Delta 433-467)$ or Runx2 (1-516)) show only moderately reduced transactivation potential (i.e. from 7-8 fold to 4-5 fold). Interestingly, all three mutants displaying severely reduced transcriptional activity are expressed at comparable levels, are imported into the nucleus (Figs 4, 5) and have normal DNA binding activity (Fig. 3), yet exhibit compromised subnuclear targeting (Figs 4-6). These data strongly suggest that subnuclear targeting of Runx2 is obligatory for optimal transcriptional activity of the protein.

\section{DISCUSSION}

In the present study, we have characterized an important component of the mechanisms mediating the assembly, organization and activities of regulatory complexes within the nucleus. We report the determinants of subnuclear targeting for the bone-related Runx 2 transcription factor. We demonstrate that the endogenous Runx 2 in osteoblastic cells is localized in distinct NM-associated subnuclear foci that are resistant to biochemical fractionation and chromatin removal from the nucleus. Using a panel of deletion mutants, we find that a 38 amino acid sequence of Runx2 (aa 397-434), designated the NMTS, is necessary and sufficient for retention of Runx 2 in subnuclear foci. The NMTS of Runx 2 functions autonomously and can target a heterologous protein to subnuclear Runx 2 foci. The regulatory consequences of NMTS-mediated subnuclear targeting are directly indicated by a significant contribution to transactivation of the bone-specific osteocalcin gene, which is physiologically expressed in osteoblasts. The conservation of the NMTS in the Runx1, Runx2 and Runx 3 proteins of diverse vertebrate species (Fig. 7) suggests that intranuclear targeting represents a conserved function in transcriptional control of tissue-specific gene expression. The similarity in subnuclear targeting signals of the three Runx proteins indicates that similar mechanisms may govern subnuclear distribution of Runx proteins.

Components of nuclear architecture may influence the spatial organization of nucleic acids and regulatory proteins. Two types of interactions have been reported: stable interactions through nuclear-matrix-associated sequences designated MARs (Bode et al., 2000) and dynamic interactions involving transcription factors and tissue-specific nuclear matrix proteins (Bidwell et al., 1993; Dworetzky et al., 1992; van Wijnen et al., 1993). Distinct transcription factors exhibit characteristic subnuclear distributions. These regulatory proteins interact with DNA in a sequence-specific manner and associate with the components of nuclear architecture at distinct subnuclear sites. Such specific intranuclear domains can provide an environment that increases the probability of achieving a threshold for protein-DNA and protein-protein interactions to organize the regulatory machinery required for tissue-specific transcription. 
The Runx family of transcription factors provides a paradigm to understand the link between transcriptional regulation and nuclear architecture. Gene ablation studies suggest that Runx2 is a principal regulator of bone formation in vivo (Komori et al., 1997; Otto et al., 1997). Recently, a nonsense mutation has been reported in exon 7, which results in expression of Runx2 lacking the NMTS (Zhang et al., 2000b). This natural mutation causes the autosomal dominant human disease the cleidocranial dysplasia (CCD), which is characterized by severe craniofacial abnormalities. The C-terminus of Runx 1 containing the NMTS is a frequent target of chromosomal translocations in leukemia (Lutterbach et al., 2000; Rowley, 1998), which is consistent with physiological implications for intranuclear trafficking. Loss of the NMTS and aberrant subnuclear targeting of Runx1 has been implicated in the pathology of leukemia. Compromised subnuclear targeting of Runx2 may also contribute to the development of the $\mathrm{CCD}$ phenotype. Additional characterization of mechanisms that control localization of Runx proteins at subnuclear sites should contribute to understanding further the development of hematopoietic and skeletal disorders.

Our data suggest that optimal transactivation of the bonerestricted osteocalcin gene by Runx2 is dependent on subnuclear localization and/or intranuclear targeting of the protein. Interestingly, the NMTS of Runx2 we have identified in this study is contained within a larger region that has a transactivation function (Kanno et al., 1998; Thirunavukkarasu et al., 1998). Moreover, this region is responsible for the interaction of Runx2 with several proteins and integrates regulatory cues related to transforming growth factor $\beta$ (TGF$\beta) /$ bone morphogenetic protein 2 (BMP2) and Yes/Crk/Src signaling pathways (Hanai et al., 1999; Yagi et al., 1999; Zhang et al., 2000a). We propose that extracellular signaling and protein-protein interactions involving the C-terminus of Runx2 and bone-specific transcriptional control may converge at subnuclear foci to optimize physiological responses.

This study was supported by National Institutes of Health grants AR45688, AR45689 and DE12528. The contents are solely the responsibility of the authors and do not necessarily represent the official views of the National Institutes of Health. The authors thank Judy Rask for editorial assistance.

\section{REFERENCES}

Aronson, B. D., Fisher, A. L., Blechman, K., Caudy, M. and Gergen, J. P. (1997). Groucho-dependent and -independent repression activities of Runt domain proteins. Mol. Cell. Biol. 17, 5581-5587.

Ausubel, F. M., Brent, R., Kingston, R. E., Moore, D. D., Seidman, J. G., Smith, J. A. and Struhl, K. (1997). Current Protocols in Molecular Biology. New York: John Wiley \& Sons.

Banerjee, C., Hiebert, S. W., Stein, J. L., Lian, J. B. and Stein, G. S. (1996). An AML-1 consensus sequence binds an osteoblast-specific complex and transcriptionally activates the osteocalcin gene. Proc. Natl. Acad. Sci. USA 93, 4968-4973.

Banerjee, C., McCabe, L. R., Choi, J.-Y., Hiebert, S. W., Stein, J. L., Stein, G. S. and Lian, J. B. (1997). Runt homology domain proteins in osteoblast differentiation: AML-3/CBFA1 is a major component of a bone specific complex. J. Cell. Biochem. 66, 1-8.

Bidwell, J. P., van Wijnen, A. J., Fey, E. G., Dworetzky, S., Penman, S., Stein, J. L., Lian, J. B. and Stein, G. S. (1993). Osteocalcin gene promoterbinding factors are tissue-specific nuclear matrix components. Proc. Natl. Acad. Sci. USA 90, 3162-3166.

Bidwell, J. P., Alvarez, M., Feister, H., Onyia, J. and Hock, J. (1998). Nuclear matrix proteins and osteoblast gene expression. J. Bone Miner. Res. 13, 155-167.
Bode, J., Benham, C., Knopp, A. and Mielke, C. (2000). Transcriptional augmentation: modulation of gene expression by scaffold/matrix-attached regions (S/MAR elements). Crit. Rev. Eukaryotic Gene Expr. 10, 73-90.

Chang, K. S., Fan, Y. H., Andreeff, M., Liu, J. and Mu, Z. M. (1995). The PML gene encodes a phosphoprotein associated with the nuclear matrix. Blood 85, 3646-3653.

Chen, G. and Courey, A. J. (2000). Groucho/TLE family proteins and transcriptional repression. Gene 249, 1-16.

Davie, J. R. (1997). Nuclear matrix, dynamic histone acetylation and transcriptionally active chromatin. Mol. Biol. Rep. 24, 197-207.

Davie, J. R. (1998). Covalent modifications of histones: expression from chromatin templates. Curr. Opin. Genet. Dev. 8, 173-178.

Davie, J. R. and Chadee, D. N. (1998). Regulation and regulatory parameters of histone modifications. J. Cell. Biochem. (Suppl.) 30-31, 203-213.

DeFranco, D. B. and Guerrero, J. (2000). Nuclear matrix targeting of steroid receptors: specific signal sequences and acceptor proteins. Crit. Rev. Eukaryotic Gene Expr. 10, 39-44.

Dickinson, L. A., Joh, T., Kohwi, Y. and Kohwi-Shigematsu, T. (1992). A tissue-specific MAR/SAR DNA-binding protein with unusual binding site recognition. Cell 70, 631-645.

Ducy, P., Zhang, R., Geoffroy, V., Ridall, A. L. and Karsenty, G. (1997). Osf2/Cbfa1: a transcriptional activator of osteoblast differentiation. Cell 89, 747-754.

Dworetzky, S. I., Fey, E. G., Penman, S., Lian, J. B., Stein, J. L. and Stein, G. S. (1990). Progressive changes in the protein composition of the nuclear matrix during rat osteoblast differentiation. Proc. Natl. Acad. Sci. USA 87, 4605-4609.

Dworetzky, S. I., Wright, K. L., Fey, E. G., Penman, S., Lian, J. B., Stein, J. L. and Stein, G. S. (1992). Sequence-specific DNA-binding proteins are components of a nuclear matrix-attachment site. Proc. Natl. Acad. Sci. USA 89, 4178-4182.

Getzenberg, R. H. and Coffey, D. S. (1990). Tissue specificity of the hormonal response in sex accessory tissues is associated with nuclear matrix protein patterns. Mol. Endocrinol. 4, 1336-1342.

Getzenberg, R. H., Pienta, K. J., Ward, W. S. and Coffey, D. S. (1991). Nuclear structure and the three-dimensional organization of DNA. J. Cell. Biochem. 47, 289-299.

Gorlich, D. and Mattaj, I. W. (1996). Nucleocytoplasmic transport. Science 271, 1513-1518.

Gorlich, D. and Kutay, U. (1999). Transport between the cell nucleus and the cytoplasm. Annu. Rev. Cell Dev. Biol. 15, 607-660.

Guo, B., Odgren, P. R., van Wijnen, A. J., Last, T. J., Nickerson, J., Penman, S., Lian, J. B., Stein, J. L. and Stein, G. S. (1995). The nuclear matrix protein NMP-1 is the transcription factor YY1. Proc. Natl. Acad. Sci. USA 92, 10526-10530.

Guo, B., Aslam, F., van Wijnen, A. J., Roberts, S. G. E., Frenkel, B., Green, M., DeLuca, H., Lian, J. B., Stein, G. S. and Stein, J. L. (1997). YY1 regulates VDR/RXR mediated transactivation of the vitamin D responsive osteocalcin gene. Proc. Natl. Acad. Sci. USA 94, 121-126.

Gutierrez, J., Sierra, J., Medina, R., Puchi, M., Imschenetzky, M., Hiebert, S., van Wijnen, A., Lian, J. B., Stein, G., Stein, J. et al. (2000). Interaction of $\mathrm{CBF} \alpha / \mathrm{AML} / \mathrm{PEBP} 2 \alpha$ transcription factors with nucleosomal sequences requires flexibility in the translational positioning of the histone octamer and exposure of the Cbf $\alpha$ site. Biochemistry 39, 13565-13574.

Hanai, J., Chen, L. F., Kanno, T., Ohtani-Fujita, N., Kim, W. Y., Guo, W.H., Imamura, T., Ishidou, Y., Fukuchi, M., Shi, M. J. et al. (1999). Interaction and functional cooperation of PEBP2/CBF with smads. Synergistic induction of the immmunoglobulin germline $c \alpha$ promoter. $J$. Biol. Chem. 274, 31577-31582.

Javed, A., Gutierrez, S., Montecino, M., van Wijnen, A. J., Stein, J. L., Stein, G. S. and Lian, J. B. (1999). Multiple Cbfa/AML sites in the rat osteocalcin promoter are required for basal and vitamin $\mathrm{D}$ responsive transcription and contribute to chromatin organization. Mol. Cell. Biol. 19, 7491-7500.

Javed, A., Guo, B., Hiebert, S., Choi, J.-Y., Green, J., Zhao, S.-C., Osborne, M. A., Stifani, S., Stein, J. L., Lian, J. B. et al. (2000). Groucho/TLE/REsp proteins associate with the nuclear matrix and repress RUNX (CBF $\alpha / A M L / P E B P 2 \alpha)$ dependent activation of tissue-specific gene transcription. J. Cell Sci. 113, 2221-2231.

Javed, A., Barnes, G. L., Jassanya, B. O., Stein, J. L., Gerstenfeld, L., Lian, J. B. and Stein, G. S. (2001). runt homology domain transcription factors (Runx, Cbfa, and AML) mediate repression of the bone sialoprotein promoter: evidence for promoter context-dependent activity of $\mathrm{Cbfa}$ proteins. Mol. Cell. Biol. 21, 2891-2905.

Kanno, T., Kanno, Y., Chen, L. F., Ogawa, E., Kim, W. Y. and Ito, Y. 
(1998). Intrinsic transcriptional activation-inhibition domains of the polyomavirus enhancer binding protein 2/core binding factor alpha subunit revealed in the presence of the beta subunit. Mol. Cell. Biol. 18, 2444-2454.

Komori, T., Yagi, H., Nomura, S., Yamaguchi, A., Sasaki, K., Deguchi, K., Shimizu, Y., Bronson, R. T., Gao, Y.-H., Inada, M. et al. (1997). Targeted disruption of $\mathrm{Cbfal}$ results in a complete lack of bone formation owing to maturational arrest of osteoblasts. Cell 89, 755-764.

Lawrence, J. B., Singer, R. H. and Marselle, L. M. (1989). Highly localized tracks of specific transcripts within interphase nuclei visualized by in situ hybridization. Cell 57, 493-502.

Lemon, B. and Tjian, R. (2000). Orchestrated response: a symphony of transcription factors for gene control. Genes Dev. 14, 2551-2569.

Levanon, D., Goldstein, R. E., Bernstein, Y., Tang, H., Goldenberg, D., Stifani, S., Paroush, Z. and Groner, Y. (1998). Transcriptional repression by AML1 and LEF-1 is mediated by the TLE/Groucho corepressors. Proc. Natl. Acad. Sci. USA 95, 11590-11595.

Lutterbach, B., Westendorf, J. J., Linggi, B., Isaac, S., Seto, E. and Hiebert, S. W. (2000). A mechanism of repression by acute myeloid leukemia-1, the target of multiple chromosomal translocations in acute leukemia. J. Biol. Chem. 275, 651-656.

Mancini, M. G., Liu, B., Sharp, Z. D. and Mancini, M. A. (1999). Subnuclear partitioning and functional regulation of the Pit-1 transcription factor. J. Cell. Biochem. 72, 322-338.

McLarren, K. W., Lo, R., Grbavec, D., Thirunavukkarasu, K., Karsenty, G. and Stifani, S. (2000). The mammalian basic helix loop helix protein HES-1 binds to and modulates the transactivating function of the runtrelated factor cbfa1. J. Biol. Chem. 275, 530-538.

McNeil, S., Guo, B., Stein, J. L., Lian, J. B., Bushmeyer, S., Seto, E., Atchison, M. L., Penman, S., van Wijnen, A. J. and Stein, G. S. (1998). Targeting of the YY1 transcription factor to the nucleolus and the nuclear matrix in situ: the C-terminus is a principal determinant for nuclear trafficking. J. Cell. Biochem. 68, 500-510.

Merriman, H. L., van Wijnen, A. J., Hiebert, S., Bidwell, J. P., Fey, E., Lian, J., Stein, J. and Stein, G. S. (1995). The tissue-specific nuclear matrix protein, NMP-2, is a member of the AML/CBF/PEBP2/runt domain transcription factor family: interactions with the osteocalcin gene promoter. Biochemistry 34, 13125-13132.

Meyers, S., Downing, J. R. and Hiebert, S. W. (1993). Identification of AML1 and the $t(8 ; 21)$ translocation protein (AML-1/ETO) as sequence-specific DNA-binding proteins; the runt homology domain is required for DNA binding and protein-protein interactions. Mol. Cell. Biol. 13, 6336-6345.

Montecino, M., Pockwinse, S., Lian, J., Stein, G. and Stein, J. (1994). DNase I hypersensitive sites in promoter elements associated with basal and vitamin D dependent transcription of the bone-specific osteocalcin gene. Biochemistry 33, 348-353.

Montecino, M., Frenkel, B., Lian, J., Stein, J. and Stein, G. (1996a). Requirement of distal and proximal promoter sequences for chromatin organization of the osteocalcin gene in bone-derived cells. J. Cell. Biochem. 63, 221-228.

Montecino, M., Lian, J., Stein, G. and Stein, J. (1996b). Changes in chromatin structure support constitutive and developmentally regulated transcription of the bone-specific osteocalcin gene in osteoblastic cells. Biochemistry 35, 5093-5102.

Montecino, M., Frenkel, B., van Wijnen, A. J., Lian, J. B., Stein, G. S. and Stein, J. L. (1999a). Chromatin hyperacetylation abrogates vitamin Dmediated transcriptional upregulation of the tissue-specific osteocalcin gene in vivo. Biochemistry 38, 1338-1345.

Montecino, M., van Wijnen, A. J., Lian, J. B., Stein, J. L. and Stein, G. S. (1999b). Phosphorylation-mediated control of chromatin organization and transcriptional activity of the tissue-specific osteocalcin gene. J. Cell. Biochem. 72, 586-594.

Nickerson, J. A., Blencowe, B. J. and Penman, S. (1995). The architectural organization of nuclear metabolism. In Structural and Functional Organization of the Nuclear Matrix (eds R. Berezney and K. W. Jeon.), pp. 67-123. New York: Academic Press.

Ogawa, E., Maruyama, M., Kagoshima, H., Inuzuka, M., Lu, J., Satake, M., Shigesada, K. and Ito, Y. (1993). PEBP2/PEA2 represents a family of transcription factors homologous to the products of the Drosophila runt gene and the human AML1 gene. Proc. Natl. Acad. Sci. USA 90, 6859-6863.

Otto, F., Thornell, A. P., Crompton, T., Denzel, A., Gilmour, K. C., Rosewell, I. R., Stamp, G. W. H., Beddington, R. S. P., Mundlos, S., Olsen, B. R. et al. (1997). Cbfal, a candidate gene for cleidocranial dysplasia syndrome, is essential for osteoblast differentiation and bone development. Cell 89, 765-771.
Prince, M., Banerjee, C., Javed, A., Green, J., Lian, J. B., Stein, G. S., Bodine, P. V. and Komm, B. S. (2001). Expression and regulation of Runx2/Cbfa1 and osteoblast phenotypic markers during the growth and differentiation of human osteoblasts. J. Cell. Biochem. 80, 424-440.

Puvion-Dutilleul, F., Besse, S., Chan, E. K., Tan, E. M. and Puvion, E. (1995). p80-coilin: a component of coiled bodies and interchromatin granule- associated zones. J. Cell Sci. 108, 1143-1153.

Reyes, J.-C., Muchardt, C. and Yaniv, M. (1997). Components of the human SWI/SNF complex are enriched in active chromatin and are associated with the nuclear matrix. J. Cell Biol. 137, 263-274.

Rowley, J. D. (1998). The critical role of chromosome translocations in human leukemias. Annu. Rev. Genet. 32, 495-519.

Shopland, L. S. and Lawrence, J. B. (2000). Seeking common ground in nuclear complexity. J. Cell Biol. 150, F1-F4.

Smith, K. P., Carter, K. C., Johnson, C. V. and Lawrence, J. B. (1995). U2 and U1 snRNA gene loci associate with coiled bodies. J. Cell. Biochem. 59, 473-485.

Spector, D. L., Fu, X. D. and Maniatis, T. (1991). Associations between distinct pre-mRNA splicing components and the cell nucleus. EMBO J. 10, 3467-3481.

Stein, G. S., van Wijnen, A. J., Stein, J. L., Lian, J. B., Montecino, M., Choi, J.-Y., Zaidi, K. and Javed, A. (2000). Intranuclear trafficking of transcription factors: implications for biological control. J. Cell Sci. 113, 2527-2533.

Stenoien, D. L., Patel, K., Mancini, M. G., Dutertre, M., Smith, C. L., O'Malley, B. W. and Mancini, M. A. (2001). FRAP reveals that mobility of oestrogen receptor- $\alpha$ is ligand- and proteasome-dependent. Nat. Cell Biol. 3, $15-23$.

Thirunavukkarasu, K., Mahajan, M., McLarren, K. W., Stifani, S. and Karsenty, G. (1998). Two domains unique to osteoblast-specific transcription factor Osf2/Cbfa1 contribute to its transactivation function and its inability to heterodimerize with Cbf beta. Mol. Cell. Biol. 18, 4197-4208.

van Steensel, B., Brink, M., van der Meulen, K., van Binnendijk, E. P., Wansink, D. G., de Jong, L., de Kloet, E. R. and van Driel, R. (1995a). Localization of the glucocorticoid receptor in discrete clusters in the cell nucleus. J. Cell Sci. 108, 3003-3011.

van Steensel, B., Jenster, G., Damm, K., Brinkmann, A. O. and van Driel, R. (1995b). Domains of the human androgen receptor and glucocorticoid receptor involved in binding to the nuclear matrix. J. Cell. Biochem. 57, 465-478.

van Wijnen, A. J., Bidwell, J. P., Fey, E. G., Penman, S., Lian, J. B., Stein, J. L. and Stein, G. S. (1993). Nuclear matrix association of multiple sequence-specific DNA binding activities related to SP-1, ATF, CCAAT, C/EBP, OCT-1, and AP-1. Biochemistry 32, 8397-8402.

Wang, Q., Stacy, T., Binder, M., Marin-Padilla, M., Sharpe, A. H. and Speck, N. A. (1996). Disruption of the Cbfa2 gene causes necrosis and hemorrhaging in the central nervous system and blocks definitive hematopoiesis. Proc. Natl. Acad. Sci. USA 93, 3444-3449.

Wei, X., Samarabandu, J., Devdhar, R. S., Siegel, A. J., Acharya, R. and Berezney, R. (1998). Segregation of transcription and replication sites into higher order domains. Science 281, 1502-1505.

Wei, X., Somanathan, S., Samarabandu, J. and Berezney, R. (1999). Threedimensional visualization of transcription sites and their association with splicing factor-rich nuclear speckles. J. Cell Biol. 146, 543-558.

Yagi, R., Chen, L. F., Shigesada, K., Murakami, Y. and Ito, Y. (1999). A WW domain-containing yes-associated protein (YAP) is a novel transcriptional co-activator. EMBO J. 18, 2551-2562.

Zeng, C., van Wijnen, A. J., Stein, J. L., Meyers, S., Sun, W., Shopland, L., Lawrence, J. B., Penman, S., Lian, J. B., Stein, G. S. et al. (1997). Identification of a nuclear matrix targeting signal in the leukemia and bonerelated AML/CBF $\alpha$ transcription factors. Proc. Natl. Acad. Sci. USA 94, 6746-6751.

Zeng, C., McNeil, S., Pockwinse, S., Nickerson, J. A., Shopland, L., Lawrence, J. B., Penman, S., Hiebert, S. W., Lian, J. B., van Wijnen, A. J. et al. (1998). Intranuclear targeting of AML/CBF $\alpha$ regulatory factors to nuclear matrix-associated transcriptional domains. Proc. Natl. Acad. Sci. USA 95, 1585-1589.

Zhang, Y. W., Yasui, N., Ito, K., Huang, G., Fujii, M., Hanai, J., Nogami, H., Ochi, T., Miyazono, K. and Ito, Y. (2000a). A RUNX2/PEBP2alpha A/CBFA1 mutation displaying impaired transactivation and Smad interaction in cleidocranial dysplasia. Proc. Natl. Acad. Sci. USA 97, 1054910554.

Zhang, Y., Yasui, N., Kakazu, N., Abe, T., Takada, K., Imai, S., Sato, M., Nomura, S., Ochi, T., Okuzumi, S. et al. (2000b). PEBP2alphaA/CBFA1 mutations in Japanese cleidocranial dysplasia patients. Gene 244, 21-28. 